\title{
Therapeutic fasting as a potential effective treatment for type 2 diabetes: A 4-month case study
}

\begin{tabular}{|c|c|}
\hline $\begin{array}{l}\text { Authors: } \\
\text { Michael Ku } \\
\text { Megan J. Ram } \\
\text { Jason Fung }\end{array}$ & \\
\hline $\begin{array}{l}\text { Affiliations: } \\
{ }^{1} \text { Department } \\
\text { Neuroscience } \\
\text { Faculty of Sci } \\
\text { University, Ca }\end{array}$ & $\begin{array}{l}\text { f Psychology, } \\
\text { and Behaviour, } \\
\text { nce, McMaster } \\
\text { hada }\end{array}$ \\
\hline $\begin{array}{l}{ }^{2} \text { Intensive Die } \\
\text { Management }\end{array}$ & $\begin{array}{l}\text { ary } \\
\text { Clinic, Canada }\end{array}$ \\
\hline $\begin{array}{l}{ }^{3} \text { Department } \\
\text { Scarborough } \\
\text { Hospital, Can }\end{array}$ & $\begin{array}{l}\text { of Medicine, } \\
\text { jeneral } \\
\text { da }\end{array}$ \\
\hline $\begin{array}{l}\text { Correspondin } \\
\text { Michael Ku, } \\
\text { michael.ku.95 }\end{array}$ & $\begin{array}{l}\text { g author: } \\
\text { @gmail.com }\end{array}$ \\
\hline $\begin{array}{l}\text { Dates: } \\
\text { Received: } 22 \\
\text { Accepted: } 10 \\
\text { Published: } 15\end{array}$ & $\begin{array}{l}\text { ept. } 2017 \\
\text { Vov. } 2017 \\
\text { Dec. } 2017\end{array}$ \\
\hline $\begin{array}{l}\text { How to cite th } \\
\text { Ku M, Ramos } \\
\text { Therapeutic f } \\
\text { potential effe } \\
\text { for type } 2 \text { dial } \\
\text { 4-month case } \\
\text { resist. } 2017 ; 2 \\
\text { https://doi.or } \\
\text { v2i1.31 }\end{array}$ & $\begin{array}{l}\text { is article: } \\
\text { MJ, Fung J. } \\
\text { sting as a } \\
\text { tive treatment } \\
\text { etes: A } \\
\text { study. J. insul. } \\
\text { 1), a31. } \\
\text { /10.4102/jir. }\end{array}$ \\
\hline $\begin{array}{l}\text { Copyright: } \\
\text { (C) 2017. The } \\
\text { Licensee: AOS } \\
\text { is licensed un } \\
\text { Creative Com } \\
\text { Attribution Lic }\end{array}$ & $\begin{array}{l}\text { uthors. } \\
\text { IS. This work } \\
\text { ler the } \\
\text { nons } \\
\text { ense. }\end{array}$ \\
\hline Read online & \\
\hline 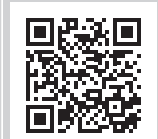 & $\begin{array}{l}\text { Scan this QR } \\
\text { code with your } \\
\text { smart phone or } \\
\text { mobile device } \\
\text { to read online. }\end{array}$ \\
\hline
\end{tabular}

Lifestyle therapy is an integral part of type 2 diabetes (T2D) management, but there remains no consensus on an optimal diet. The objective of this study is to evaluate the efficacy of therapeutic fasting as a treatment for T2D. This case follows a male T2D patient treated at the Intensive Dietary Management Clinic in Scarborough, Ontario, over a 4-month period. The patient's initial fasting regimen consisted of a 24-h fast, three times a week. Over the course of treatment, the patient gradually extended his fasting period, eventually fasting for $42 \mathrm{~h}$, two to three times a week. By the end of treatment, the patient's weight was reduced by $17.8 \%$ and his waist circumference was reduced by $11.0 \%$. In addition, the patient's glycated haemoglobin levels decreased from $7.7 \%$ to $7.2 \%$, and he was able to completely discontinue his insulin treatment, despite over a decade of insulin usage. The patient did not find it difficult to adhere to the fasting schedule and did not experience any hypoglycaemic episodes or other significant adverse effects. These observations suggest that therapeutic fasting may be a viable treatment option for T2D patients.

\section{Introduction}

Type 2 diabetes (T2D), which is characterised by elevated insulin resistance and an integral part of the metabolic syndrome, is associated with many complications. ${ }^{1}$ The prevalence of this disease has been rising quickly in the past few decades. Approximately $10 \%$ of the United States and Canadian population have a diagnosis of T2D, with another $20 \%$ of Canadians and 30\% of Americans labelled as prediabetic. ${ }^{2}$ The prevalence of diabetes is expected to rapidly increase in the future, with Canada estimating a 41\% increase in diabetes prevalence from 2016 to $2026 .{ }^{3}$ The morbidity and mortality rate associated with T2D is high, with a substantial economic burden: more than $20 \%$ of healthcare spending in the United States is targeted at diabetic patients. ${ }^{4}$

Insulin and oral hypoglycaemic agents are commonly used to manage elevated blood glucose, but disease progression often necessitates an increase in medication dosage. However, more intensive treatments, including more frequent use of insulin or other drugs, may increase the risk of mortality because of cardiovascular disease. ${ }^{5}$ The World Health Organization, American Diabetes Association and Diabetes Canada all maintain that lifestyle therapy is the cornerstone of management; however, there remains no consensus about an optimal diet for T2D. ${ }^{6,7,8,9}$ Many diets have been tested including various restrictions on calories, carbohydrates and dietary fat. Low-fat diets appear to be ineffective as a treatment for T2D. ${ }^{10}$ Studies suggest that low-carbohydrate diets are superior to other dietary approaches in managing T2D, but the majority of these studies only investigate short-term results. ${ }^{11}$ Compliance and the ability to adhere to these diets may also play a role in their effectiveness as treatments.

Bariatric surgery has been proved to be effective in reducing patient blood sugar levels, medication use and weight. ${ }^{12,13}$ However, this option is both invasive and costly and carries the potential for a number of side effects. In the Swedish Obese Subjects (SOS) study, 13\% of patients experienced surgical complications, with $2.2 \%$ of patients requiring reoperation. ${ }^{14}$ Thus, it remains inaccessible or unattractive to many patients.

Another dietary intervention offers a similar severe caloric restriction - fasting. Therapeutic fasting may be an effective, natural alternative dietary treatment, offering similar caloric restriction and hormonal benefits without the cost or invasiveness of surgical intervention. ${ }^{15}$ Unlike starvation, which is involuntary and uncontrolled, therapeutic fasting is defined as the controlled and voluntary abstinence from all calorie-containing foods and drinks for a specified period of time.

One review on intermittent fasting demonstrated that weight loss is a fairly consistent finding amongst fasting studies. ${ }^{16}$ Another review found randomised control trials of fasting to have 
significant improvements in weight and risk-related outcomes and also found that fasting was associated with a lower prevalence of coronary artery disease and diabetes diagnosis in observational outcome studies. ${ }^{17}$ However, it should be noted that the majority of these studies have only examined the effects of fasting over a short period of time.

The present case study seeks to further explore the effects of therapeutic fasting and its effectiveness as a treatment for T2D by following a T2D patient through a 4-month intermittent fasting treatment.

\section{Case}

This case documents a patient referred to the Intensive Dietary Management (IDM) Clinic in Toronto, Canada, for insulin-dependent T2D. The IDM clinic works with clients to adopt a low-carbohydrate diet and use intermittent fasting for weight loss and control of T2D.

A 69-year-old man diagnosed with T2D for 35 years was initially seen in consultation on 07 April 2017. At the time, the patient was taking 160 units of insulin daily and $1000 \mathrm{mg}$ of Metformin twice a day to manage his diabetes. His medications included the following:

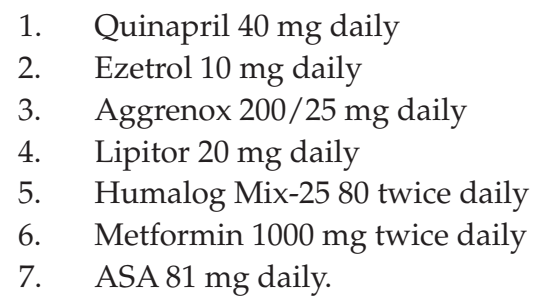

The patient has been on Metformin for 35 years and on insulin treatment for the past 11 years. He has never used any other forms of diabetic medication. He has no known microvascular or macrovascular complications.

Other significant medical history includes hypertension, hypercholesterolaemia, a transient ischemic attack (2002) and bilateral cataracts. At baseline, the patient weighed $92.6 \mathrm{~kg}$, with a body mass index of 28.4 and a waist circumference of $109 \mathrm{~cm}$.

\section{Treatment}

The patient attended an initial 6-h nutritional seminar outlining the basics of a low-carbohydrate diet and intermittent fasting, as well as an introduction on the topics of obesity, T2D, fasting, body composition, insulin resistance and meal timing. The initial fasting prescription introduced a 24-h fast, three times a week. In addition, he reduced his dietary intake of sugars and refined carbohydrates and increased his consumption of natural fats. The patient was instructed to consume approximately $70 \%$ of his daily calories from natural fats, $20 \%$ from proteins (both plant and animal based) and $10 \%$ from net carbohydrates from leafy greens and non-starchy vegetables. Permitted fluids included water, non-sugared tea, black coffee and homemade bone broth.
One month into the treatment, as the patient began feeling more confident with the programme, he requested that his fasting period should be extended and began fasting between 24 and $36 \mathrm{~h}$, three times a week. After the second month, he again pushed his fasting schedule to between 24 and $42 \mathrm{~h}$, two to three times a week.

On eating days, the patient ate in two 90-min eating windows. The 24-h fasting protocol consisted of fasting between dinner on a certain day and the dinner on the next day. The 36-h fasting protocol consisted of fasting between dinner on one day and breakfast 2 days later. The 42-h fasting protocol consisted of fasting between dinner on one day and lunch 2 days later.

A physician and a dietary counsellor monitored the patient every 2 weeks until insulin was discontinued, after which he was followed monthly. The patient tested his blood sugar four times daily during the insulin-weaning period. Target daily blood sugars were between $7 \mathrm{mmol} / \mathrm{L}$ and $10 \mathrm{mmol} / \mathrm{L}$.

Food diary, blood sugar log and adherence to fasting schedules were discussed at each visit. The team made adjustments to fasting regimen and medication dosage. In addition, the patient's weight, waist circumference and blood pressure were measured and recorded at each visit. As $\mathrm{HbA} 1 \mathrm{c}$ represents a weighted average over 120 days, this was measured every few months, rather than at every visit. Blood tests were conducted monthly.

\section{Results}

The patient completely discontinued his insulin treatment after 2 months of therapeutic fasting in conjunction with a substantial reduction in glycated haemoglobin levels, from $7.7 \%$ to $7.2 \%$ (Figure 1). He remains on his oral hypoglycaemic medication, $1000 \mathrm{mg}$ of Metformin twice a day. No symptomatic episodes of hypoglycaemia were reported by the patient.

The patient reduced his body weight and waist size. Over the 4 months of treatment, the patient's weight decreased by $17.8 \%$ (from $92.6 \mathrm{~kg}$ to $76.1 \mathrm{~kg}$ ) and waist circumference by 11\% (from $109 \mathrm{~cm}$ to $97 \mathrm{~cm}$ ) (see Figures 2 and 3). Table 1

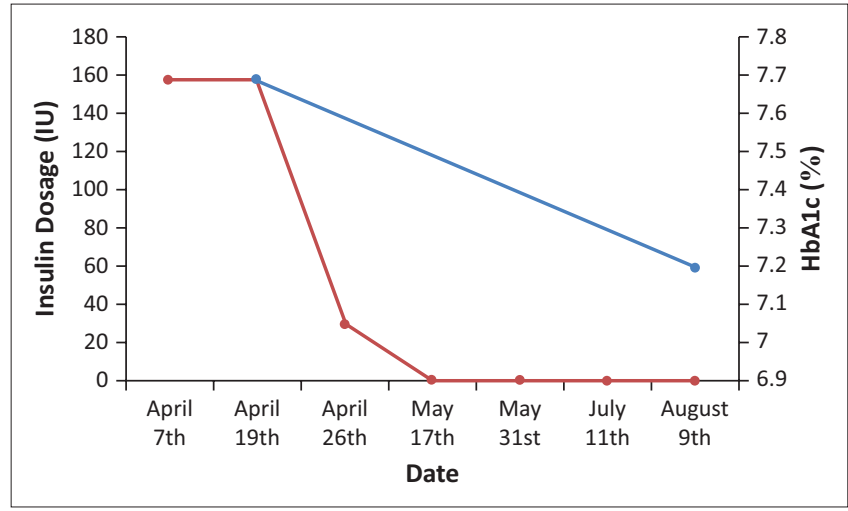

FIGURE 1: Change in insulin dosage and glycosylated haemoglobin over the course of treatment. 


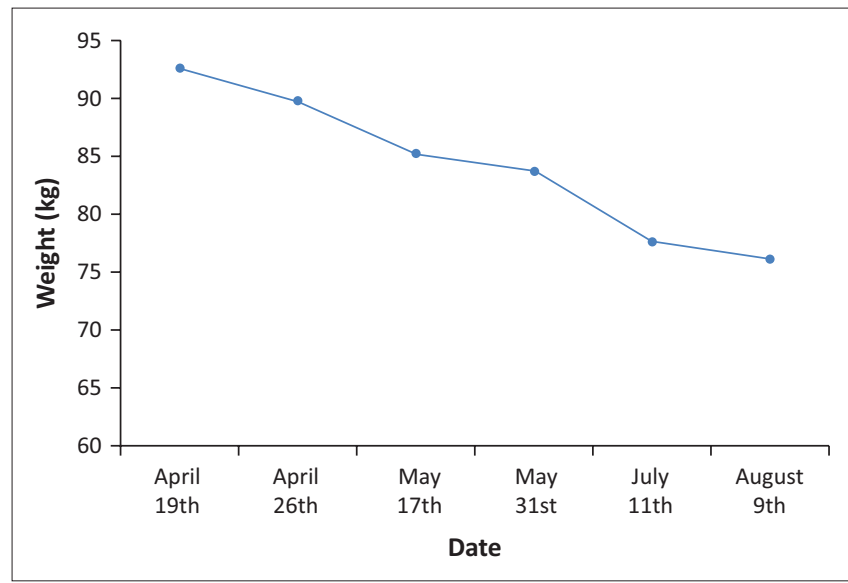

FIGURE 2: Change in body weight over the course of treatment.

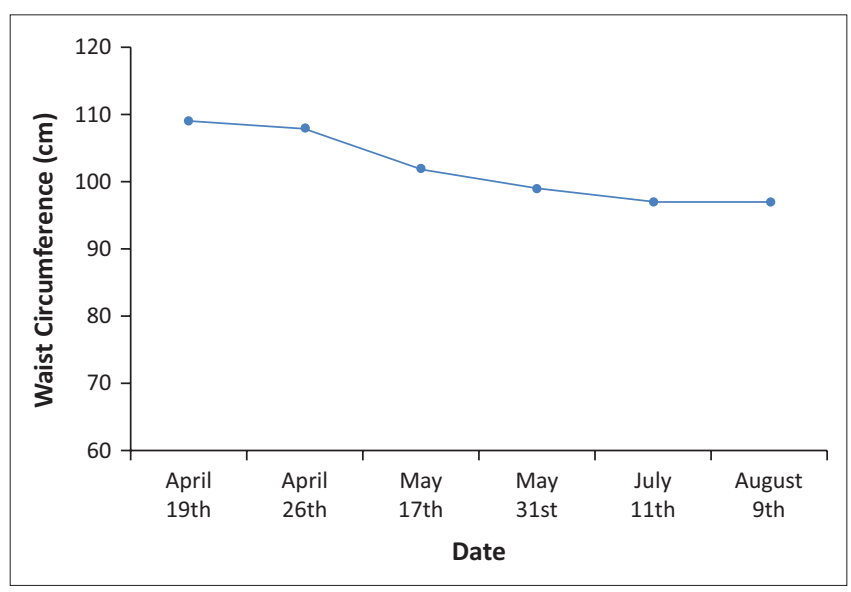

FIGURE 3: Change in waist circumference over the course of treatment.

TABLE 1: Patient measurements at each visit.

\begin{tabular}{lclccc}
\hline Date & Insulin & Medication & Weight $(\mathbf{k g})$ & Waist $(\mathbf{c m})$ & HbA1c (\%) \\
\hline 19 April 2017 & 160 & Metformin 1 $\mathrm{g}^{2}$ & 92.6 & 109 & 7.7 \\
26 April 2017 & 30 & Metformin 1 $\mathrm{g}^{2}$ & 89.8 & 108 & N/A \\
17 May 2017 & 30 & Metformin 1 $\mathrm{g}^{2}$ & 85.2 & 102 & N/A \\
31 May 2017 & 0 & Metformin 1 $\mathrm{g}^{2}$ & 83.7 & 99 & N/A \\
11 July 2017 & 0 & Metformin 1 $\mathrm{g}^{2}$ & 77.6 & 97 & N/A \\
09 August 2017 & 0 & Metformin 1 $\mathrm{g}^{2}$ & 76.1 & 97 & 7.2 \\
\hline
\end{tabular}

summarises a full breakdown of the patient's measurements during each visit.

Overall, the patient stated that he did not find it difficult to stick to his fasting schedule and is confident in continuing his fasting regimen. He reported normal energy levels and noted no significant or minor adverse effects because of fasting or the change in diet. This was assessed through verbal consultation during the patient's visits to the clinic. No adverse effects were detected through the monthly blood tests.

\section{Discussion}

This case report demonstrates that therapeutic fasting in conjunction with a low-carbohydrate diet can be an effective treatment option for T2D. The treatment worked quickly to reduce blood glucose and insulin resistance. Despite over a decade of insulin usage, the patient was able to completely discontinue his insulin treatment in only 4 months of dietary treatment. Simultaneously, he reduced his glycated haemoglobin levels, weight and waist circumference, indicating that the underlying insulin resistance of T2D was significantly improved.

Although glycated haemoglobin levels only dropped by $0.5 \%$, which may seem like a small reduction over 4 months, the importance is in realising that the patient is able to control and reduce his blood sugar levels on his own with a dietary intervention and no longer needs to rely on insulin to manage his blood sugar. The observation that the patient was able to completely come off of insulin, while not only managing his blood sugar levels but being able to reduce them, supports the effectiveness of the treatment.

The rapid reversal of $\mathrm{T} 2 \mathrm{D}$ is also seen in studies of bariatric surgery. The Surgical Treatment and Medications Potentially Eradicate Diabetes Efficiently (STAMPEDE) study examined 150 T2D patients who either received intensive medical therapy alone or medical therapy in addition to a Roux-en-Y gastric bypass or sleeve gastrectomy. ${ }^{18}$ Both surgical groups were significantly more likely to reach target $\mathrm{HbA1c}$ levels of $6.0 \%$ or less and reduce or eliminate diabetic medications, with lowered fasting plasma glucose and improved insulin sensitivity compared with the intensive medical therapy group. Unsurprisingly, weight loss was also greater in the surgical groups. These differences were achieved within only 3 months after treatment, and are durable, having been observed in both a 3-year and 5-year follow-up. ${ }^{13,19}$

The SOS study comparing surgical and medical weight loss found that the surgical group had significantly greater weight loss and had lower overall mortality. ${ }^{20}$ Similar to the STAMPEDE study, weight loss occurs almost immediately after treatment. At a 10-year follow-up, the surgical group had substantial improvements in glucose, insulin, uric acid, triglyceride and HDL levels, as well as reduced blood pressure, waist circumference and incidence of diabetes. ${ }^{21}$

This is a consistent finding amongst most studies examining bariatric surgery. A review by Pories found that bariatric surgery reverses diabetes in four out of five patients and produces remarkable and durable weight loss. ${ }^{22}$ The review also identifies the rapid remission of T2D as the most remarkable effect of bariatric surgery, noting diabetes generally clears within a matter of days following surgical treatment.

Low-carbohydrate diets have also demonstrated effectiveness in managing T2D. A prospective study following more than 200 T2D subjects assigned to a low-carbohydrate diet $(<30$ $\mathrm{g}$ /day) observed significant decreases in weight and $\mathrm{HbA} 1 \mathrm{c}$ by day 70 of the intervention, with medications halted or reduced in $63 \%$ of participants. ${ }^{23} \mathrm{~A}$ comprehensive review of dietary carbohydrate restriction studies concludes that lowcarbohydrate diets should be the first approach in diabetes management, providing a wealth of evidence to support this 
argument. ${ }^{24}$ The authors note, however, the lack of long-term randomised controlled trials. While this may be the case, the short-term effects of low carbohydrate interventions are impressive and should not be ignored.

There is strong evidence that bariatric surgery is an effective treatment for T2D and moderate evidence that lowcarbohydrate diets are also effective. Therapeutic fasting may deliver many of the same benefits with far greater ease of implementation and at no cost.

Jackson et al. observed a 2-week water-only fast in seven obese diabetic and seven obese non-diabetic women and found reduced plasma triglyceride and blood glucose levels in both groups, along with an improvement in glucose tolerance in the diabetic group. ${ }^{25}$ A 2014 study by Nuttall et al. compared a standard (control) diet, low-carb diet and fasting diet (3 day, water and calorie-free beverages only fast) in seven male T2D patients using a randomised crossover design and found that the fasting diet was associated with the lowest glucose concentration and insulin response and had the most pronounced weight loss. ${ }^{26}$ Arnason et al. assigned 10 T2D patients to a 2-week intermittent fasting period and found significant decreases in weight, BMI and morning glucose levels. ${ }^{27} \mathrm{Li}$ et al. conducted a randomised control study, comparing a group of $16 \mathrm{~T} 2 \mathrm{D}$ patients who were assigned to a 7-day fasting programme followed by dietary advice with a group of 16 T2D patients who were given only dietary advice. They found significant reductions in weight loss, waist circumference and blood pressure in the fasting group compared with the control group. ${ }^{28}$

Studies examining intermittent fasting on overweight but non-diabetic populations have found that fasting lowers body weight, fasting glucose levels, fasting insulin concentration and improves insulin sensitivity, concluding that fasting may be effective in reducing the risk of T2D. ${ }^{29,30}$

As one may note, most studies examining intermittent fasting are short term, and the overall quantity of data is preliminary. The present case report, however, examines an intermittent fasting intervention over a 4-month period and demonstrates that the beneficial effects of fasting are continuous and observed over the entirety of this period. The patient's ability to comply with an intermittent fasting regimen for this length of time suggests that fasting may be a long-term and sustainable form of treatment. More rigorous and longerterm studies may be able to demonstrate just how far the benefits of fasting extend.

\section{Conclusion}

The existing research suggests that therapeutic fasting has shown promising results and may be effective for both the prevention and the management of T2D. Furthermore, it has the advantages of being both affordable and accessible worldwide.

\section{Acknowledgements Competing interests}

The authors declare that they have no financial or personal relationships which may have inappropriately influenced them in writing this article.

\section{Author contributions}

M.K. authored the case report, while J.F. and M.R., as the clinic's directors, were involved with data collection and overseeing the treatment program. J.F. was also largely involved in the writing process, providing edits, revisions, and guidance.

\section{References}

1. Krentz AJ. Type 2 diabetes and atherosclerotic cardiovascular disease: Do they share common antecedents? Br J Diabetes Vasc Dis. 2002;2(5):370-378. https:// doi.org/10.1177/14746514020020050501

2. Menke A, Casagrande S, Geiss L, Cowie CC. Prevalence of and trends in diabetes among adults in the United States, 1988-2012. JAMA. 2015;314(10):1021-1029. https://doi.org/10.1001/jama.2015.10029

3. Diabetes in Canada Fact Sheet [homepage on the Internet]. Canadian Diabetes Association: Diabetes Charter for Canada; 2016 [cited 2017 Aug 1]. Available from: https://www.diabetes.ca/getmedia/513a0f6c-b1c9-4e56-a77c6a492bf7350f/diabetes-charter-backgrounder-national-english.pdf.aspx

4. Diabetes Latest - Fact Sheet [homepage on the Internet]. Centers for Disease Control and Prevention: CDC Features; 2016 [cited 2017 Aug 1]. Available from: https://www.cdc.gov/chronicdisease/resources/publications/aag/pdf/2016/ diabetes-aag.pdf

5. Skyler JS, Bergenstal R, Bonow RO, et al. Intensive glycemic control and the prevention of cardiovascular events: Implications of the ACCORD, ADVANCE, and VA diabetes trials. Circulation. 2009;119(2):351-357. https://doi.org/10.1161/ CIRCULATIONAHA.108.191305

6. Diabetes Fact Sheet [homepage on the Internet]. World Health Organization: Media Centre; 2017 [cited 2017 Aug 1]. Available from: http://www.who.int/ mediacentre/factsheets/fs312/en/

7. American Diabetes Association. 4. Lifestyle management. Diabetes Care. 2017;40(Suppl. 1):S33-S43. https://doi.org/10.2337/dc17-S007

8. Managing Weight \& Diabetes [homepage on the Internet]. Diabetes Canada: Diabetes \& You; 2017 [cited 2017 Aug 1]. Available from: https://www.diabetes. $\mathrm{ca} /$ diabetes-and-you/healthy-living-resources/weight-management/managingweight-diabetes

9. Sawyer L, Gale EAM. Diet, delusion and diabetes. Diabetologia. 2009;52(1):1-7.

10. Tobias DK, Chen M, Manson JE, Ludwig DS, Willett W, Hu FB. Effect of low-fat diet interventions versus other diet interventions on long-term weight change in adults: A systematic review and meta-analysis. Lancet Diabetes Endocrinol. 2015;3(12):968-979. https://doi.org/10.1016/S2213-8587(15)00367-8

11. Meng Y, Bai H, Wang S, Li Z, Wang Q, Chen L. Efficacy of low carbohydrate diet for type 2 diabetes mellitus management: A systematic review and meta-analysis of randomized controlled trials. Diabetes Res Clin Pract. 2017;131:124-131. https:// doi.org/10.1016/j.diabres.2017.07.006

12. Brethauer SA, Aminian A, Romero-Talamás $H$, et al. Can diabetes be surgically cured? Long-term metabolic effects of bariatric surgery in obese patients with type 2 diabetes mellitus. Ann Surg. 2013;258(4):628. https://doi.org/10.1097/ SLA.0b013e3182a5034b

13. Schauer PR, Bhatt DL, Kirwan JP, et al. Bariatric surgery versus intensive medical therapy for diabetes - 3-year outcomes. N Engl J Med. 2014;370(21):2002-2013. https://doi.org/10.1056/NEJMoa1401329

14. Sjöström L. Surgical intervention as a strategy for treatment of obesity. Endocrine. 2000;13(2):213-230. https://doi.org/10.1385/ENDO:13:2:213

15. Kroeger CM, Klempel MC, Bhutani S, Trepanowski JF, Tangney CC, Varady KA. Improvement in coronary heart disease risk factors during an intermittent fasting/ calorie restriction regimen: Relationship to adipokine modulations. Nutr Metab. 2012;9(1):98. https://doi.org/10.1186/1743-7075-9-98

16. Patterson RE, Laughlin GA, Sears DD, et al. Intermittent fasting and human metabolic health. J Acad Nutr Dietetics. 2015;115(8):1203. https://doi.org/ 10.1016/j.jand.2015.02.018

17. Horne BD, Muhlestein JB, Anderson JL. Health effects of intermittent fasting: Hormesis or harm? A systematic review. Am J Clin Nutr. 2015;102(2):464-470. https://doi.org/10.3945/ajcn.115.109553

18. Schauer PR, Kashyap SR, Wolski K, et al. Bariatric surgery versus intensive medical therapy in obese patients with diabetes. N Engl J Med. 2012;366(17):1567-1576. https://doi.org/10.1056/NEJMoa1200225 
19. Schauer PR, Bhatt DL, Kirwan JP, et al. Bariatric surgery versus intensive medical therapy for diabetes - 5-year outcomes. N Engl J Med. 2017;376(7):641-651. https://doi.org/10.1056/NEJMoa1600869

20. Sjöström L, Narbro K, Sjöström CD, et al. Effects of bariatric surgery on mortality in Swedish obese subjects. N Engl J Med. 2007;2007(357):741-752. https://doi. org/10.1056/NEJMoa066254

21. Sjöström L, Lindroos AK, Peltonen $M$, et al. Lifestyle, diabetes, and cardiovascular risk factors 10 years after bariatric surgery. N Engl J Med. 2004;351(26):26832693. https://doi.org/10.1056/NEJMoa035622

22. Pories WJ. Bariatric surgery: Risks and rewards. J Clin Endocrinol Metab. 2008;93(11 Suppl. 1):S89-S96. https://doi.org/10.1210/jc.2008-1641

23. Hallberg S, McKenzie A, Creighton B, et al. Improvement in atherogenic dyslipidemia at 70 days following a reduced carbohydrate intervention for treatment of type 2 diabetes. J Clin Lipidol. 2016;10(3):665. https://doi. org/10.1016/j.jacl.2016.03.030

24. Feinman RD, Pogozelski WK, Astrup A, et al. Dietary carbohydrate restriction as the first approach in diabetes management: Critical review and evidence base. Nutrition. 2015;31(1):1-3. https://doi.org/10.1016/j.nut.2014.06.011
25. Jackson RA, Moloney M, Lowy $\mathrm{C}$, et al. Differences between metabolic responses to fasting in obese diabetic and obese nondiabetic subjects. Diabetes. 1971;20(4):214-227. https://doi.org/10.2337/diab.20.4.214

26. Nuttall FQ, Almokayyad RM, Gannon MC. Comparison of a carbohydrate-free diet vs. fasting on plasma glucose, insulin and glucagon in type 2 diabetes. Metabolism. 2015;64(2):253-262. https://doi.org/10.1016/j.metabol.2014.10.004

27. Arnason TG, Bowen MW, Mansell KD. Effects of intermittent fasting on health markers in those with type 2 diabetes: A pilot study. World J Diabetes. 2017;8(4):154. https://doi.org/10.4239/wjd.v8.i4.154

28. Li C, Sadraie B, Steckhan N, et al. Effects of a one-week fasting therapy in patients with type-2 diabetes mellitus and metabolic syndrome - A randomized controlled explorative study. Exp Clin Endocrinol Diabetes. 2017;125(9):618-624. https:// doi.org/10.1055/s-0043-101700

29. Barnosky AR, Hoddy KK, Unterman TG, Varady KA. Intermittent fasting vs daily calorie restriction for type 2 diabetes prevention: A review of human findings. Transl Res. 2014;164(4):302-311. https://doi.org/10.1016/j.trsl.2014.05.013

30. Halberg $N$, Henriksen $M$, Söderhamn $N$, et al. Effect of intermittent fasting and refeeding on insulin action in healthy men. J Appl Physiol. 2005;99(6):2128-2136. https://doi.org/10.1152/japplphysiol.00683.2005 